\title{
Arch and access vessel complications in penetrating aortic ulcer managed with thoracic endovascular aortic repair
}

\author{
Gabriele Piffaretti ${ }^{1}$, Federico Fontana ${ }^{2}$, Marco Tadiello ${ }^{1}$, Chiara Guttadauro ${ }^{1}$, Filippo Piacentino ${ }^{2}$, \\ Ruth L. Bush ${ }^{3}$, Anna Maria Socrate ${ }^{4}$, Matteo Tozzi ${ }^{1}$ \\ ${ }^{1}$ Vascular Surgery, ${ }^{2}$ Interventional Radiology, Department of Medicine and Surgery, Circolo University Teaching Hospital, University of Insubria \\ School of Medicine, Varese, Italy; ${ }^{3}$ University of Houston College of Medicine, Houston, TX, USA; ${ }^{4}$ Vascular Surgery, ASST Ovest Milano, \\ Legnano, Italy \\ Correspondence to: Gabriele Piffaretti, MD, PhD. Vascular Surgery, Department of Medicine and Surgery, Circolo University Teaching Hospital, \\ University of Insubria School of Medicine, Via Guicciardini, 9, Varese 21100, Italy. Email: gabriele.piffaretti@uninsubria.it.
}

\begin{abstract}
Background: To analyze our experience and to describe access and arch-related challenges when performing thoracic endovascular aortic repair (TEVAR) for penetrating aortic ulcers (PAUs).

Methods: This is a single-center, observational, cohort study. Between October 2003 and February 2019, 48 patients with PAU were identified; 37 (77.1\%) treated with TEVAR were retrospectively analyzed. Primary major outcomes were early (<30 days) and late survival, freedom from aortic-related mortality (ARM), and a composite endpoint of arch/vascular access-related complications.

Results: On admission, 17 (45.9\%) patients were symptomatic with 4 (10.8\%) presenting with rupture. Inhospital mortality was $8.1 \%(n=3)$. We observed 10 (27.0\%) arch/access-related complications. There were $4(10.8 \%)$ arch issues: 2 transient ischemic attacks and 2 retrograde acute type A dissections which required emergent open conversion for definitive repair. Access issues occurred in $6(16.2 \%)$ patients: 3 (8.1\%) required common iliac artery conduit, and $1(2.7 \%)$ patient required iliac artery angioplasty to deliver the stent-graft. In addition, 2 (5.4\%) patients developed access complications which required operative repair [femoral patch angioplasty $(n=2)$, and femoral pseudoaneurysmectomy $(n=1)]$. Arch/access-related mortality rate was $5.4 \%(n=2)$ and median follow-up was 24 (range, 1-156; IQR, 3-52) months. Estimated survival was $87.1 \%$ (standard error: 0.6; 95\% CI: $71.2-84.9 \%$ ) at 1 year, and $63.3 \%$ (SE: 0.9; 95\% CI: 44.1-79\%) at 4 years. Estimated freedom from reintervention was $88.9 \%$ (SE: 0.5; 95\% CI: 74.8-95.6\%) at 1 year, and $84.2 \%$ (SE: 0.7; 95\% CI: 67.3$93.2 \%)$ at 4 years. No arch/access-related issues developed during the follow-up period.

Conclusions: Our experience confirms that vascular access and aortic arch issues are still a challenging aspect of performing TEVAR for PAUs. Our cumulative $27 \%$ rate of access/arch issues is lower than previously reported due to both technological advancements and meticulous management of both access routes and arch anatomy.
\end{abstract}

Keywords: Thoracic penetrating aortic ulcers (thoracic PAUs); access complications; retrograde type A dissection; stroke after thoracic endovascular aortic repair (stroke after TEVAR)

Submitted Mar 11, 2019. Accepted for publication Jun 03, 2019.

doi: 10.21037/acs.2019.06.07

View this article at: http://dx.doi.org/10.21037/acs.2019.06.07

\section{Introduction}

The treatment of penetrating atherosclerotic ulcers (PAU) remains controversial. There is clinical overlap between PAU and aortic ulcer-like projections (ULP) that has been reported in several series over the last two decades contributing to confusion regarding frequency, prognosis and management of these entities (1). Despite these reporting inconsistencies, both entities have been considered adequate anatomic targets for thoracic 

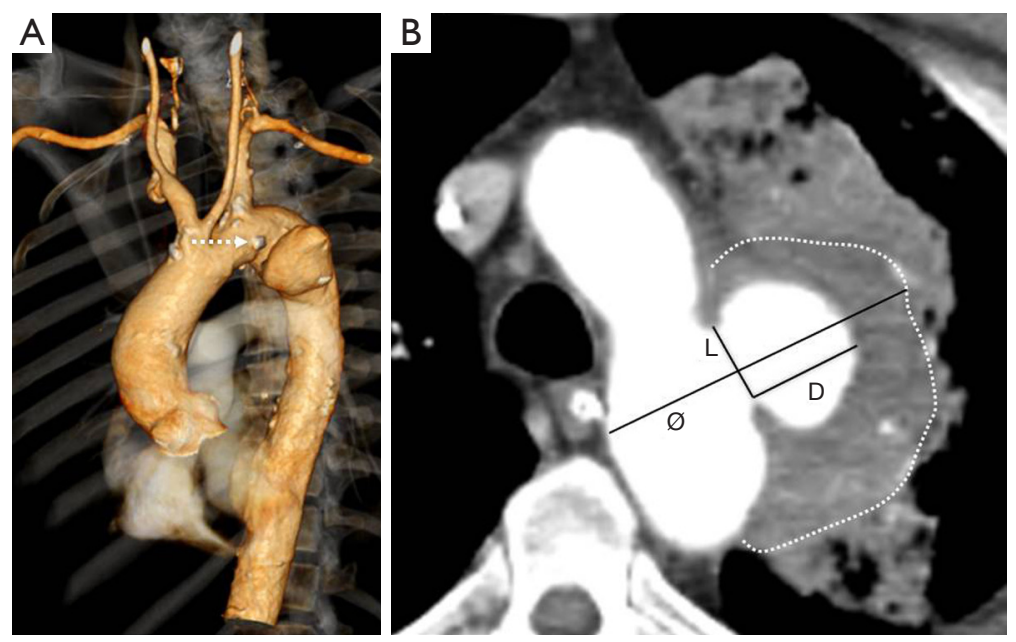

Figure 1 Preoperative CTA with volume rendering 3D reconstruction (A) of a distal aortic arch PAU. Calcifications (dotted arrow) are typically present at the edges of the ulcer. Axial image (B) shows the measurements of the ulcer: diameter (Ø), depth (D), and length (L). PAU, penetrating aortic ulcer.

endovascular aortic repair (TEVAR) $(2,3)$. Most PAUs are seen in the setting of diffuse and dense atherosclerotic disease, possibly including severe peripheral occlusive disease (4-6). These characteristics may preclude a suitable TEVAR due to disease of the access vessel and increased risk of neurologic complications due to the endovascular maneuvers in the aortic arch which often has a heavy burden of vulnerable atheroma $(4,7)$.

The purpose of this study is to describe our experience, approach, and outcomes with aortic arch and vascular access challenges encountered during TEVAR performed for PAUs.

\section{Methods}

\section{Patient cohort}

This is a single center, observational cohort study of consecutive patients with PAU treated by TEVAR between October 2003 and February 2019. Due to the unpredictable natural history of thoracic PAUs, our institution adopted an aggressive approach in favor of operative repair $(8,9)$. The following are indications for surgical repair for thoracic PAU:

- Asymptomatic lesion with diameter $\geq 30 \mathrm{~mm}$ and/or depth $\geq 10 \mathrm{~mm}$ (Figure 1A,B);

* Asymptomatic progressively enlarging "blister-like" lesion (Figure 2);

* Saccular pseudoaneurysm $\geq 50 \mathrm{~mm}$ or aortic lesion evolution into classic aortic dissection with detection of perfused true and false lumens;
* Symptomatic lesion (typical chest/back pain) in the presence of signs of impending rupture (crescent sign, pleural effusion) and/or persisting symptoms despite best medical treatment;

* "Shaggy aorta" with visceral/peripheral embolization syndrome;

- Free (hemothorax) or contained (periaortic hematoma) rupture (Figure 2C,D,E).

Patients diagnosed and treated for PAU located in the ascending aorta were not included in this analysis. The CONSORT diagram indicates all patients with thoracic PAU during the period of study, including the patient population from whom this series was derived (Figure 3). Informed consent for intervention was signed by each patient and approval for this specific study was obtained by the local Institutional Review Board, according to the National Policy Privacy Act regarding retrospective analysis of anonymized data. For this study, all cases were reviewed and debated by three senior authors [one vascular surgeon (GP) and two interventional radiologists (FF, FP)] with $>20$ years of experience in the diagnosis and treatment of thoracic aortic diseases. For the final analysis, the end of the study was March $1^{\text {st }}, 2019$.

\section{Aortic lesion assessment and definitions}

Each patient's operative risk profile was defined after a multidisciplinary evaluation which included the 

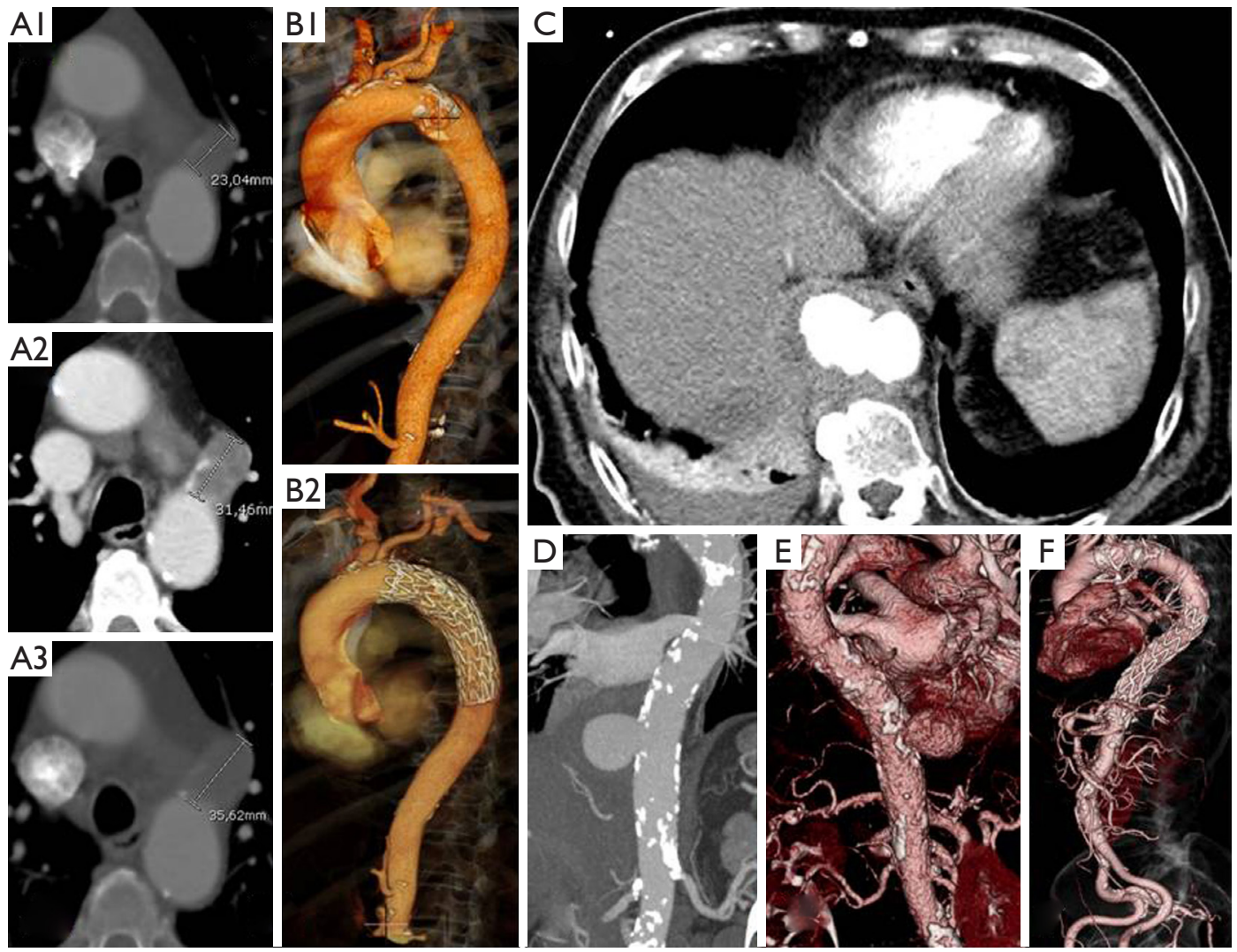

Figure 2 Two cases of PAU of the distal aortic arch (A,B) and of the descending thoracic aorta (C,D,E,F). Axial images (A1-A3) show the enlargement evolution of a "blister-like" lesion over a 2-year period. Volume rendering 3D reconstructions show, preoperatively (B1), the location and the typical calcifications surrounding focally only the aorta affected by the PAU. Postoperatively (B2) the result of TEVAR after 24 months follow-up with the complete exclusion of the lesion, and the good apposition of the SG at the inner curve in such a Romanesque aortic arch. Preoperative CTA of a contained rupture (C) of a descending PAU with the typical calcifications of the entire aorta (D). Volume rendering $3 \mathrm{D}$ reconstructions of the same case: preoperative (E) and postoperative (F) after 12 months of follow-up. PAU, penetrating aortic ulcer; TEVAR, thoracic endovascular aortic repair.

clinical visit, laboratory blood tests and biomarkers (leucocytes, procalcitonin, and C-reactive protein), and cardiorespiratory tests $(10,11)$. Although a definitive imaging-based distinction has not been established by any radiologic/pathologic correlative study, we distinguished PAU from ULP. PAU is a focal lesion that ulcerates the intima and disrupts the internal elastic lamina of the aortic wall, has calcifications of the ulcer edges that are typical of atherosclerotic plaques, and could be accompanied by a hematoma localized around the lesion (Figures $1 B, 2 B, C, D, E$ ) $(1,12)$. Ulcer measurements included maximal aortic diameter, depth, and length of intimal defect (Figure 1A) $(9,13)$. The maximum aortic diameter and wall features were evaluated by visual inspection, comprising the largest external diameter and eventual wall hematoma thickness.
The severity of the atheromatous disease was assessed by preoperative computed-tomography scans and scored using a modified scale which has been shown to correlate stroke risk with shaggy aorta defined by the presence of an irregular and protruding atheroma thickness $>5 \mathrm{~mm}$ (14). Three categories of aortic arch shape were defined according to the classification of $\mathrm{Ou}$ et al. (15). The "gothiclike" configuration was characterized by a steep angulation between the ascending and descending aorta with a short transverse portion of the aortic arch. The crenel configuration was characterized by a "rectangular-like" form with a normal length of the horizontal aorta and the Romanesque aortic arch has a smooth semicircular form. Patient co-morbidities, PAU morphologic characteristics, postoperative outcomes, and follow-up index (FUI) were 


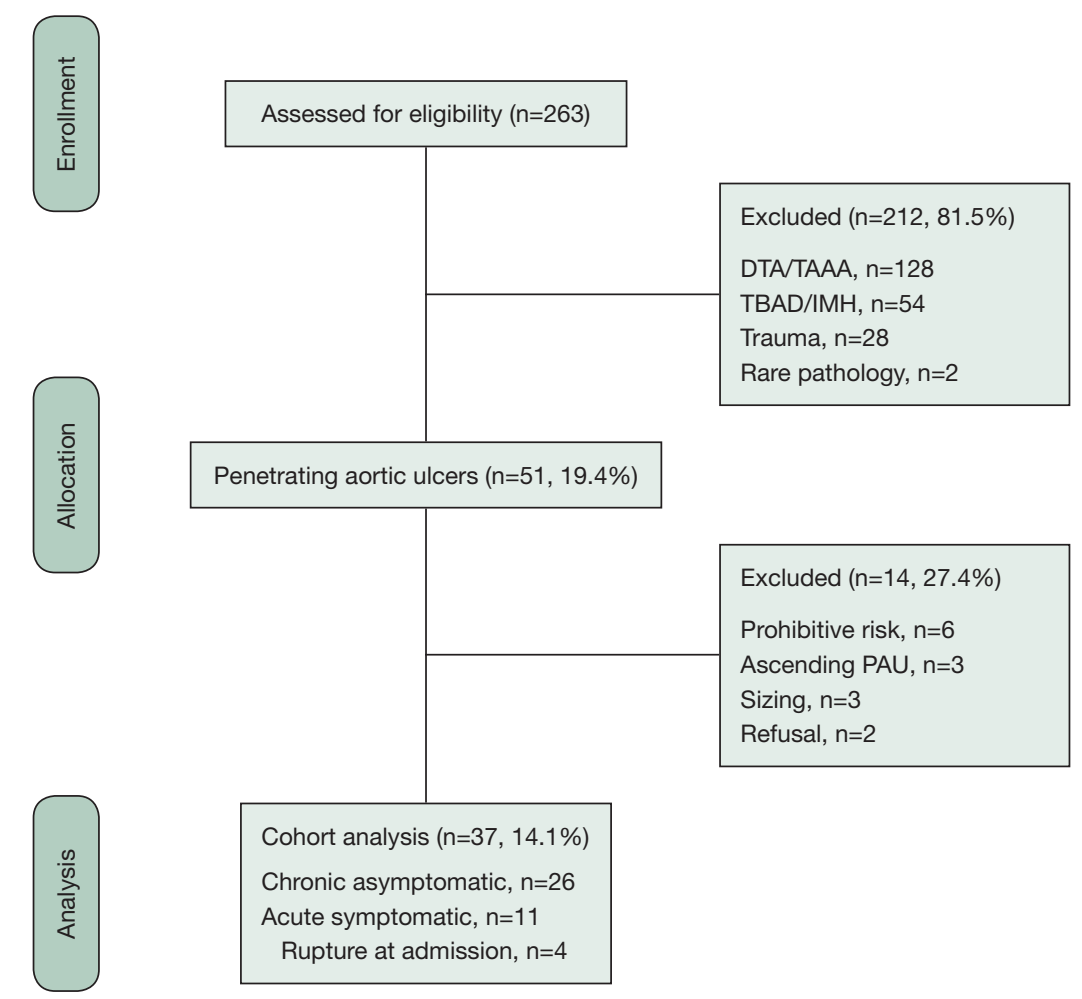

Figure 3 Consort diagram indicating all descending and thoracoabdominal aneurysm patients during the period of study, including the patient population from which this series was derived. DTA, descending thoracic aneurysm; TAAA, thoraco-abdominal aortic aneurysm; TBAD, type B aortic dissection; IMH, intramural hematoma; PAU, penetrating aortic ulcer.

defined according to recommended reporting standards documents (16-19). Favorable aortic remodeling was defined by the complete exclusion of the ULPs and diameter reduction $\geq 10 \mathrm{~mm}$ from the preoperative diameter in the absence of any stent-graft (SG) induced intimal defects (Figure 4). Major outcomes measures were early (<30 days) and late survival, freedom from aortic-related mortality (ARM), and a composite outcome of arch and/ or access-related issues.

\section{Treatment protocol and follow-up}

All operations were performed in the operating theatre using general anesthesia. For focal, saccular lesions, healthy landing zones of $15 \mathrm{~mm}$ from the affected zone were used in all cases (20). Oversizing of the endovascular grafts was $10 \%$ or less. Graft materials and manufacturers are reported in the Appendix (supplemental material). The protocol for spinal cord ischemia (SCI) prevention agreed with the position statement of the European Association for Cardio-Thoracic Surgery (EACTS) vascular domain (21).
Post-deployment angioplasty was only used selectively to ensure SG-wall apposition. During follow-up, triple-phase computed tomography angiography (CTA) was performed at 1 and 12 months, and on an annual basis thereafter. Maximum aortic diameters were measured on preoperative and the most recent postoperative CTA.

\section{Statistical analysis}

Clinical data were prospectively recorded and tabulated in a Microsoft Excel (Microsoft Corp, Redmond, Wash) database. Statistical analysis was performed with SPSS (Version 25.0 IBM SPSS Inc. Chicago, IL, USA). Continuous variables were tested for normal distribution by the Kolmogorov-Smirnov test and compared between groups with unpaired Student's $t$-test for normally distributed values, otherwise the Mann-Whitney $U$ test was employed. For categorical variables, we used the Pearson's $\chi^{2}$-test or Fisher exact tests as appropriate. Continuous variables were presented with mean \pm standard deviation (SD) and interquartile (IQR) range, otherwise medians with 

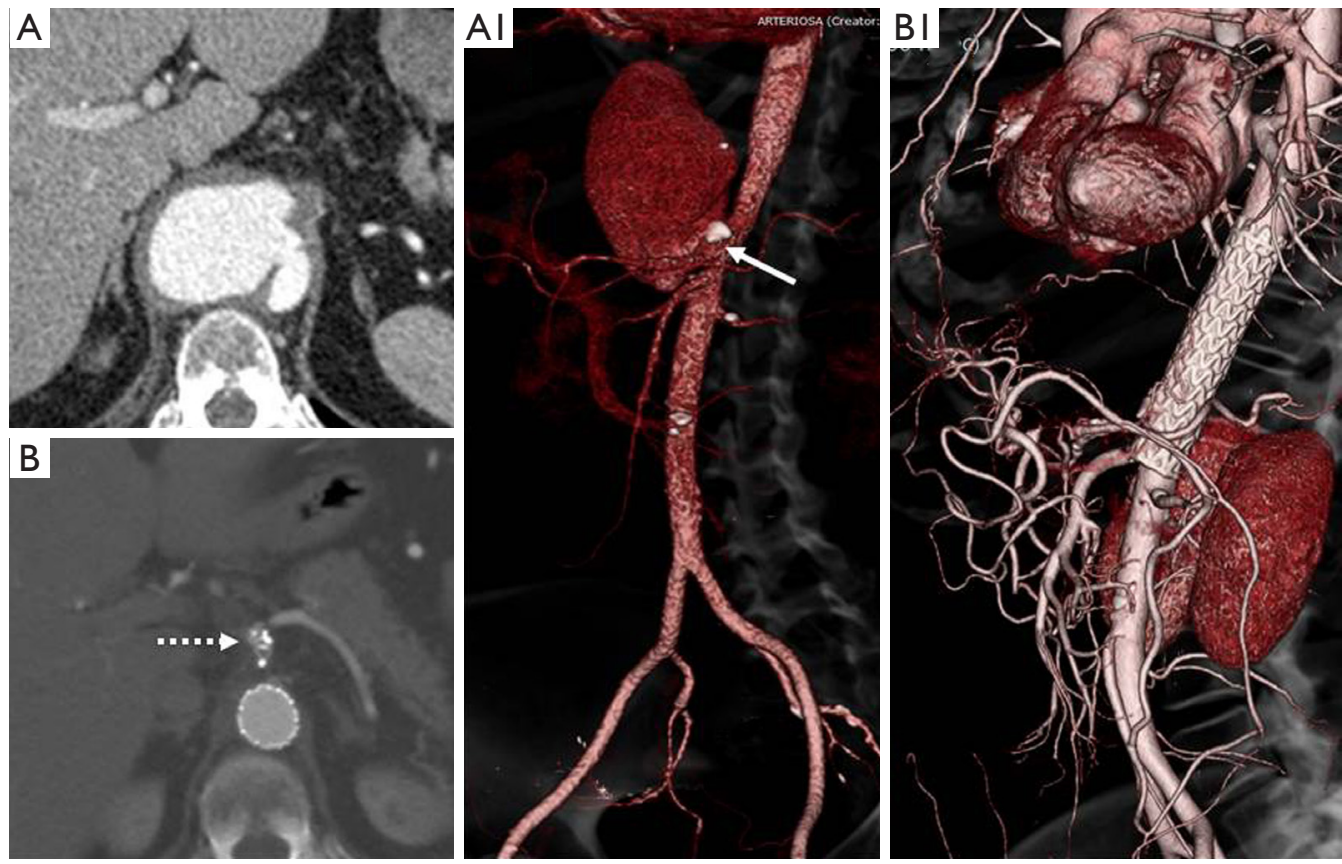

Figure 4 A case of "giant" PAU of the hiatus (A) with the typical calcification at the edge of the ulcer (A1) clearly visible at the preoperative volume rendering 3D reconstruction. Follow-up CTA at 36 months shows the complete shrinkage of the lesion after plug embolization of the celiac trunk (B, dotted arrow) and TEVAR with intentional overstenting of the celiac trunk and distal landing zone at the superior boarder of the superior mesenteric artery (B1). PAU, penetrating aortic ulcer; TEVAR, thoracic endovascular aortic repair.

range were applied. Categorical variables were presented using frequencies and percentages. A stepwise logistic regression model was developed to identify patients and procedural variables associated with arch/access issues. The model was built using variables that demonstrated a $\mathrm{P}$ value $<0.20$ in univariable analysis. The strength of the association of variables with arch/access issues was estimated by calculating the odds ratio (OR) and $95 \%$ confidence intervals (CI). The model was calibrated by the Hosmer-Lemeshow goodness-of-fit test, as well as residual diagnostics (deviance and $\mathrm{df} \beta$ ); model discrimination was evaluated by using the area under the receiver operating characteristic (AUROC) curve. Kaplan-Meier curves, \pm standard error (SE) and 95\% CI, estimated the probability of survival or freedom from any adverse aortic events. All reported $\mathrm{P}$ values were 2 -sided, and $\mathrm{P}$ value $<0.05$ was considered significant.

\section{Results}

\section{Cohort data}

We treated 37 PAUs with TEVAR during the study period.
At presentation, patients were symptomatic for thoracic pain $(n=8,21.6 \%)$, hoarseness $(n=3,8.1 \%)$, peripheral embolization syndrome $(\mathrm{n}=2,5.4 \%)$, or hemoptysis $(\mathrm{n}=2$, $5.4 \%)$. Rupture with hemorrhagic shock was present in $4(10.8 \%)$ patients. Demographic data and risk factors are presented in Table 1. To summarize, patients who had arch and/or access issues had a history of previous cerebrovascular accidents ( $40 \%$ vs. $3.7 \%$, OR: 8.23 , $\mathrm{P}=0.014)$, more synchronous aortic lesions (70\% vs. $22.2 \%$, OR: 7.31, $\mathrm{P}=0.017$ ), and showed a trend of smaller access vessel diameter $(6.7 \pm 1.5$ vs. $7.7 \pm 1.5 \mathrm{~mm}, \mathrm{P}=0.081)$. There were no patients with known connective tissue disorders.

\section{PAU morphology}

Morphologic characteristics of PAUs and access vessels are reported in Table 2. Twenty-four $(64.9 \%)$ PAUs presented as a saccular pseudoaneurysm, while a "blisterlike" morphology was present in 5 (13.5\%). A "shaggy aorta" was seen in 3 (8.1\%) patients. In 29 (78.4\%) cases, the PAU was a single lesion in the descending thoracic aorta and in $8(21.6 \%)$, we detected $\geq 2$ lesions. In 3 (8.1\%) 
Table 1 Demographic data, co-morbidities, and risk factors of the cohort of 37 PAUs treated with TEVAR

\begin{tabular}{|c|c|}
\hline Variable & $\mathrm{n}(\%)$ \\
\hline \multicolumn{2}{|l|}{ Demographic data } \\
\hline M:F (ratio) & $24(64.9): 13(35.1)$ \\
\hline Age (mean \pm SD) & $73 \pm 9($ IQR, 68-78) \\
\hline \multicolumn{2}{|l|}{ Risk factors } \\
\hline Hypertension & $35(94.6)$ \\
\hline Hyperlypemia & $20(54.1)$ \\
\hline COPD & $16(43.2)$ \\
\hline Obesity (BMI >30) & $14(37.8)$ \\
\hline Synchronous aneurysmal disease & $13(35.1)$ \\
\hline AAA & 11 \\
\hline Ascending & 1 \\
\hline Iliac & 1 \\
\hline Ischemic heart disease & $10(27.0)$ \\
\hline Chronic atrial fibrillation & $9(24.3)$ \\
\hline Diabetes & $6(16.2)$ \\
\hline Previous cerebrovascular events & $5(13.5)$ \\
\hline Renal insufficiency (GFR $<30 \mathrm{~mL} / \mathrm{min}$ ) & $5(13.5)$ \\
\hline Previous AAA surgery & $3(8.1)$ \\
\hline \multicolumn{2}{|l|}{ Risk profile } \\
\hline Free rupture & $4(10.8)$ \\
\hline EuroSCORE* & $\begin{array}{l}27 \pm 18.5 \\
(I Q R, 14.5-32.3)\end{array}$ \\
\hline
\end{tabular}

*, http://euroscore.org/calc.html. TEVAR, thoracic endovascular aortic repair; PAU, penetrating aortic ulcer; $n$, number; $M$, male; $F$, female; IQR, interquartile range; SD, standard deviation; CODP, chronic obstructive pulmonary disease; BMI, body mass index; AAA, abdominal aortic aneurysm; GFR, glomerular filtration rate.

patients, there was also a PAU seen in the infrarenal aorta. Arch atheroma grade 3 or higher was present in 8 (21.6\%) cases, and an associated local intramural hematoma was present in $14(37.8 \%)$ cases. The aortic arch configuration was Romanesque in $28(75.7 \%)$ patients, "Gothic-like" in 4 $(10.8 \%)$, and crenel in $2(5.4 \%)$.

\section{Data of operative repair}

Femoral artery access was used for endovascular graft

\begin{tabular}{ll}
\multicolumn{2}{l}{ Table 2 Morphologic characteristics of the 37 PAUs } \\
\hline Variable & $\mathrm{n}(\%)$ \\
\hline Aortic segment & $3(8.1)$ \\
Transverse arch & $13(35.1)$ \\
Distal arch & $19(51.4)$ \\
Descending & $2(5.4)$ \\
Hiatus & \\
Sizing (mm \pm SD) & $48 \pm 12[40-55]$ \\
Diameter & $29 \pm 13[19-36]$ \\
Depth & $20 \pm 9[14-22]$ \\
Length & $12 \pm 7.5[5-19]$ \\
Distance from CT & \\
Access vessel & $7.4 \pm 1.6[7-8]$ \\
Best femoral diameter $(m m \pm S D)$ & \\
Calcium score & $11(29.7)$ \\
Absent & $7(18.9)$ \\
Mild & $9(24.3)$ \\
Extensive but limited & $10(27.0)$ \\
Extensive and severe & \\
\hline
\end{tabular}

PAU, penetrating aortic ulcer; $n$, number; IQR, interquartile range; $\mathrm{SD}$, standard deviation; $\mathrm{CT}$, celiac trunk.

delivery in $34(91.9 \%)$ cases. Mean aortic length coverage was $148 \pm 15 \mathrm{~mm}$ (range, 100-320; IQR, 100-150). The origin of the left subclavian artery was completely covered and revascularized during the same operation in $6(16.2 \%)$ patients. Additional vascular procedures were performed in $15(40.5 \%)$ patients with 5 involving the access vessel. Operative details of all SG interventions are reported in Table 3.

\section{Early outcomes}

Primary technical success was $94.6 \%(\mathrm{n}=35)$. In 1 (2.7\%) case, a low-flow proximal type 1 endoleak was sealed with an extension cuff, and a retrograde acute type A dissection (RATAD) required emergent open conversion for repair. Eleven $(29.7 \%)$ patients were admitted to the intensive care unit (ICU) following TEVAR and all but 2 were extubated in the immediate postoperative period. Most $(n=9)$ of these patients remained in ICU $<24$ hours after the intervention, 


\begin{tabular}{|c|c|}
\hline Variable & n (\% or IQR) \\
\hline \multicolumn{2}{|l|}{ Stent-graft } \\
\hline Free-flow & $19(51.3)$ \\
\hline Diameter $(m m \pm S D)$ & $34 \pm 4($ IQR, 34-37) \\
\hline $1 \mathrm{sg}$ & $31(83.8)$ \\
\hline 2 sgs & $6(16.2)$ \\
\hline \multicolumn{2}{|l|}{ Operative data } \\
\hline General anesthesia & $37(100.0)$ \\
\hline Femoral access & 34 (91.9) \\
\hline LSA coverage & $6(16.2)$ \\
\hline Aortic coverage $(\mathrm{mm} \pm \mathrm{SD})$ & $148 \pm 5($ IQR, 100-150) \\
\hline$<20$ & $30(81.1)$ \\
\hline$\geq 20$ & 7 (18.9) \\
\hline Intervention $(\min \pm \mathrm{SD})$ & $121 \pm 105(\mathrm{IQR}, 60-120)$ \\
\hline Blood loss (median, mL) & 50 (IQR, 50-200) \\
\hline Contrast $(\min \pm \mathrm{SD})$ & $91 \pm 40($ IQR, 60-120) \\
\hline \multicolumn{2}{|l|}{ Adjunctive procedures } \\
\hline CS bypass + LSA plug & $5(13.5)$ \\
\hline EVAR & $3(8.1)$ \\
\hline Femoral patch & $2(5.4)$ \\
\hline LSA "chimney" & $1(2.7)$ \\
\hline SAT debranching & $1(2.7)$ \\
\hline Visceral debranching & $1(2.7)$ \\
\hline CT plug & $1(2.7)$ \\
\hline Renal artery stenting & $1(2.7)$ \\
\hline Iliac artery PTA & $1(2.7)$ \\
\hline Pseudoaneurysmectomy & $1(2.7)$ \\
\hline
\end{tabular}

$\mathrm{n}$, number; SG, stent-graft; mm, millimeters; $\mathrm{cm}$, centimeters; min, minutes; $\mathrm{mL}$, milliliters; IQR, interquartile range; SD, standard deviation; CS, carotid-to-subclavian; LSA, left subclavian artery; EVAR, endovascular abdominal aortic repair; PTA, percutaneous transluminal angioplasty.

while 2 required prolonged (>10 days) ICU stay. In-hospital mortality was $8.1 \%(n=3)$. There was no statistically significant difference in mortality between patients who receive either urgent or elective treatment $[\mathrm{n}=2(18.2 \%) \mathrm{vs}$. $\mathrm{n}=1(3.8 \%), \mathrm{P}=0.144]$. The causes of death were RATAD
Table 4 Postoperative complications, grading classification, and treatment of patients treated with TEVAR

\begin{tabular}{|c|c|c|c|}
\hline Complication grade & n (\%) & Treatment & $\begin{array}{l}\text { Perioperative } \\
\text { outcome }\end{array}$ \\
\hline \multicolumn{4}{|l|}{ Mild } \\
\hline SVS grade $1 \mathrm{SCl}$ & $1(2.7)$ & Rehabilitation & Recover \\
\hline $\begin{array}{l}\text { Pulmonary } \\
\text { embolism }\end{array}$ & $1(2.7)$ & LMWH & Uneventful \\
\hline $\begin{array}{l}\text { Post-implant } \\
\text { syndrome }\end{array}$ & $1(2.7)$ & Conservative & Recover \\
\hline Atrial fibrillation & $1(2.7)$ & Amiodarone & Recover \\
\hline \multicolumn{4}{|l|}{ Moderate } \\
\hline Acute kidney injury & $3(8.1)$ & Hydratation & Recover \\
\hline TIA & $2(5.4)$ & Rehabilitation & Recover \\
\hline Wound hematoma & $1(2.7)$ & $\begin{array}{l}\text { Surgical } \\
\text { exploration }\end{array}$ & Recover \\
\hline Wound infection & $1(2.7)$ & $\begin{array}{l}\text { Surgical } \\
\text { debridement }\end{array}$ & Recover \\
\hline Sepsis & $1(2.7)$ & $\begin{array}{l}\text { Antibiotic } \\
\text { therapy }\end{array}$ & Recover \\
\hline \multicolumn{4}{|l|}{ Severe } \\
\hline RATAD & $2(5.4)$ & Open repair & Dead \\
\hline Pyothorax & $1(2.7)$ & VAT evacuation & Recover \\
\hline $\begin{array}{l}\text { Small bowel } \\
\text { infarction }\end{array}$ & $1(2.7)$ & Resection & Dead \\
\hline Pneumonia & $1(2.7)$ & $\begin{array}{l}\text { Antibiotic } \\
\text { therapy }\end{array}$ & Recover \\
\hline
\end{tabular}

TEVAR, thoracic endovascular aortic repair; n, number; LMWH, low molecular weight heparin; $\mathrm{SCI}$, spinal cord ischemia; TIA, transient ischemic attack; SVS, Society for Vascular Surgery; RATAD, retrograde acute type A aortic dissection; VAT, videoassisted thoracic evacuation.

$(\mathrm{n}=2)$ and small bowel infarction $(\mathrm{n}=1)$. Table 4 presents postoperative complications. There was no incidence of fatal or disabling stroke. The median length of stay was 6 days (range, 1-135; IQR, 4-7).

\section{Arch and access-related issues}

Overall, we observed $10(27.0 \%)$ arch and/or accessrelated issues. Of the 4 (10.8\%) arch issues, 2 transient ischemic attacks resolved spontaneously without any 


\begin{tabular}{|c|c|}
\hline Cause of death & $\mathrm{n}$ \\
\hline \multicolumn{2}{|l|}{ Cardiovascular } \\
\hline Acute myocardial infarction & 4 \\
\hline Left heart insufficiency & 1 \\
\hline Stroke & 1 \\
\hline Aorto-esophageal fistula & 1 \\
\hline Aorto-bronchial fistula & 1 \\
\hline Multiple organ failure & 2 \\
\hline \multicolumn{2}{|l|}{ Gastrointestinal } \\
\hline Necrotic pancreatitis & 1 \\
\hline Liver cirrhosis & 1 \\
\hline Senile marasmus & 2 \\
\hline Chronic renal failure & 1 \\
\hline Sepsis & 1 \\
\hline Respiratory failure & 1 \\
\hline Alzheimer disease & 1 \\
\hline Traumatic brain hemorrhage & 1 \\
\hline
\end{tabular}

residual deficit or disability, while 2 RATADs required emergent open conversion (immediate postoperative, $\mathrm{n}=1$; later on day $3^{\text {rd }}$ postoperatively, $\mathrm{n}=1$ ). Both patients died on postoperative days 1 and 3 . Access issues occurred in $6(16.2 \%)$ patients. In 4 cases, the small caliber of the femoral vessels necessitated a planned conduit on the common iliac artery $(n=3)$ or iliac angioplasty $(n=1)$ to introduce the SG. In addition, 2 (5.4\%) patients developed access complications following TEVAR which required surgical reconstruction [femoral patch angioplasty $(\mathrm{n}=2)$ and femoral pseudoaneurysmectomy $(\mathrm{n}=1)]$. The mortality rate in patients with arch/access issues was $5.4 \%(n=2)$. Diabetes, a previous history of cerebrovascular accident, severely atheromatous arch, and associated aneurysmal abdominal aortic disease was found to be associated with access and arch issues. However, multivariable analysis demonstrated that a previous history of cerebrovascular accidents (OR: 2.72; 95\% CI: 1.198-4.321, $\mathrm{P}=0.031$ ) was significantly associated with arch/access vessel issues. The AUROC for this model was 0.681 , suggesting the ability to identify individuals who will have arch/access issue. The
Hosmer-Lemeshow goodness-of-fit test was not significant $\left[\chi^{2}(6 \mathrm{df})=4.54 ; \mathrm{P}=0.604\right]$, indicating that there was not statistically significant departure from a perfect fit.

\section{Late outcomes}

Median follow-up was 24 (range, 1-156; IQR, 3-52) months: FUI was $0.9 \pm 0.1$. During the follow-up period, 17 (50\%) patients died: causes of death reported in Table 5 . Overall, estimated survival was $87.1 \%$ (SE: 0.6 ; $95 \%$ CI: $71.2-84.9 \%$ ) at 1 year and $63.3 \%$ (SE: $0.9 ; 95 \%$ CI: $44.1-79 \%)$ at 4 years (Figure $5 A$ ). Twenty-four (70.6\%) patients had an available CTA at 12 months, $14(41.2 \%)$ at 36 months, and 9 (26.5\%) had follow-up CTA $\geq 60$ months. Favorable aortic remodeling was observed in 30 (88.2\%) cases. No additional arch/access-related issues developed during the follow-up. TEVAR-related adverse events were observed in $4(11.4 \%)$ patients. There were 2 fistulas (aortobronchial and aorto-esophageal) that led to sudden death at the time of the re-admission, a proximal type 1 endoleak in a patient who declined endovascular re-intervention $(\mathrm{n}=1)$, and a SG-induced intimal defect that is still under surveillance without any aortic-related adverse event $(n=1)$. The estimated freedom-from reintervention rate was $88.9 \%$ (SE: 0.5 ; 95\% CI: 74.8-95.6\%) at 1 year and $84.2 \%$ (SE: 0.7; 95\% CI: $67.3-93.2 \%$ ) at 4 years (Figure $5 B$ ).

\section{Discussion}

Thoracic PAUs have been defined as an ideal surgical indication for TEVAR. The lesions tend to be focal and develop in the relatively straight segment of the descending thoracic aorta in $59-100 \%$ of the cases. A recent consensus statement recommends TEVAR to be the first line option in the treatment of PAUs $(1,4)$. However, consistent with other aortic diseases, TEVAR may be challenging if there are anatomical constraints for current SG technology.

Typically, patients with PAUs have severely calcified, small diameter iliac and -femoral vessels and may have high grade atheroma in the aortic arch which may preclude repair or increase the risk during TEVAR (22). Therefore, careful evaluation of the most appropriate and safest access for SG insertion is of utmost importance. The surgeon needs to be familiar with alternative access options such as the retroperitoneal exposure of iliac arteries $(23,24)$. Interestingly, peripheral arterial obstructive disease involving iliac and/or femoral vessels has only been reported as a risk factor by a few authors (Table 6). A comprehensive 

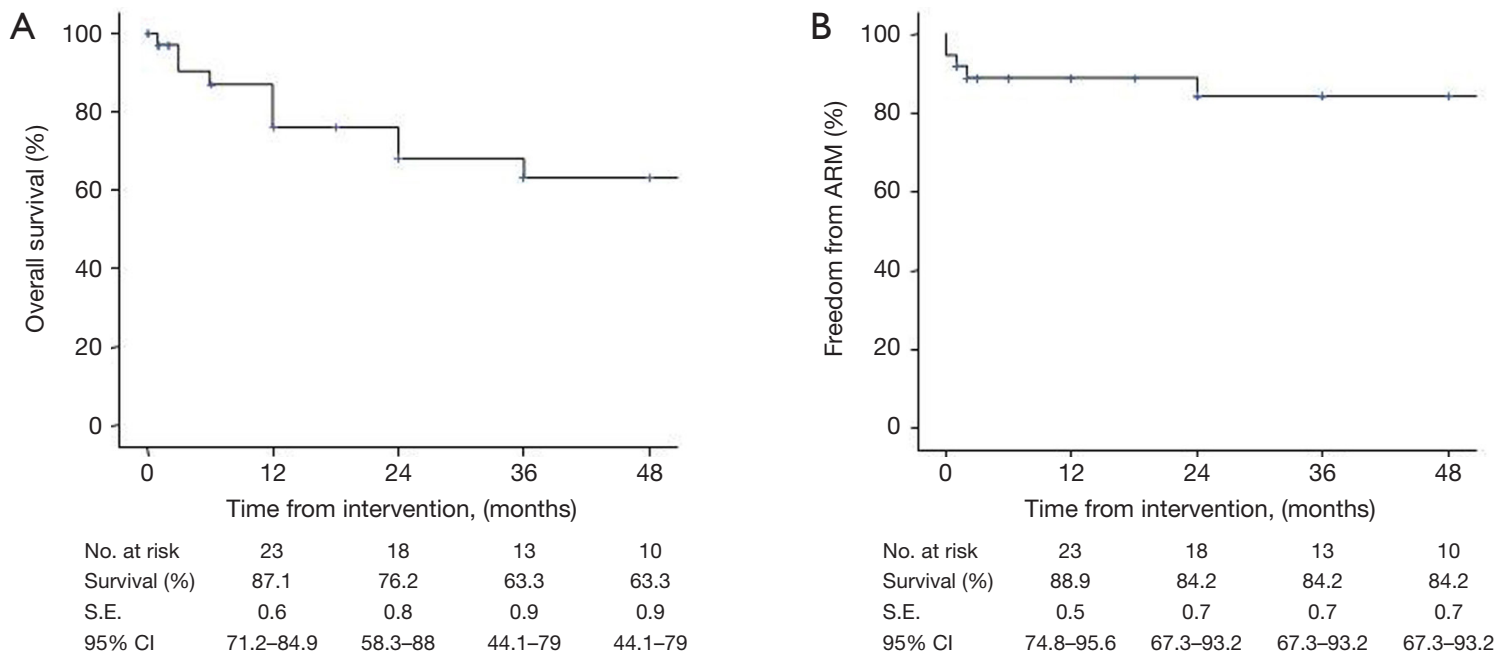

Figure 5 Kaplan-Meier estimates of the overall survival (A) and freedom from ARM (B). ARM, aortic-related mortality.

literature review revealed that an iliac conduit for stent graft delivery was required in up to $46 \%$ of the cases (5,11,25-32). Furthermore, small caliber or severely diseased iliac and femoral arteries may be prone to complications such as disruption, thrombosis, dissection and false aneurysm $(7,22,23,33,34)$. In our experience, a vascular access issue was encountered in $16.2 \%$ of the cases. This rate includes both common iliac artery conduits and unplanned vascular reconstruction to repair iatrogenic iliac or femoral injuries. These two different situations highlight the severity of the atherosclerotic burden that affects access vessels in these patients.

Our data yield additional observations. First, while the overall rate of access-related issues is less than previously reported, our $5.4 \%$ rate of access complication is in line with the $0-5.2 \%$ range observed in our literature review (5,11,25-32). Second, our infrequent use of conduits may reflect meticulous preoperative planning or the lower profile of newer endovascular devices. Regardless, access complications remain a concern (24). Our complication rate is similar to clinical series from the past decade when SG devices were of larger profile and had bulky introducer sheaths. Indeed, these data emphasize that the access artery quality may be compromised by the severity of the atherosclerotic disease especially in patients with PAUs (31).

From an anatomical point of view, the extent of the involved aorta is much less in PAU than aneurysmal disease and the lesion itself is also often short in length $(6,11)$. These anatomical features may be, for example, favorable by limiting an important complication such as SCI occurrence but do impact on other threatening complications especially when located in the aortic arch $(2,7,28)$. For example, the risk of stroke in patients with PAUs has been reported to be similar for TEVAR and open surgery ( $4 \%$ vs. $7 \%$, respectively) (1). In our series, a history of previous cerebrovascular events, not correlated to carotid artery disease, independently predicted the occurrence of an arch issue. This data finds support in previous experience that showed TEVAR in patients with a history of stroke had the highest perioperative stroke rate (14). These results show how the underlying burden of atheromatous disease, that is common in this population, makes the aortic arch vulnerable to complications during TEVAR (35).

Another important aortic arch issue in our experience was the occurrence of RATAD. In our complete TEVAR experience, this complication has only been seen in the PAU cohort. Our observation is somewhat unexpected as recent large registries have reported a $0-2 \%$ prevalence of RATAD after TEVAR for PAU $(36,37)$. In our opinion, our two instances should not be ascribed only to a potentially fragile aorta. We believe that one RATAD was triggered by ballooning of the SG at its proximal edge, while the other event occurred in a patient whose aorta was potentially suitable for off-pump debranching (ascending aorta of $40 \mathrm{~mm}$ ).

Patients with PAUs have not been considered ideal candidates for conventional open surgical repair due to the systemic distribution of atherosclerotic disease $(1,4,6)$. We believe this observation hold for patients undergoing TEVAR $(3,9,22,26,28,32,34)$. First, while TEVAR may have decreased in-hospital mortality by $39 \%$ compared 


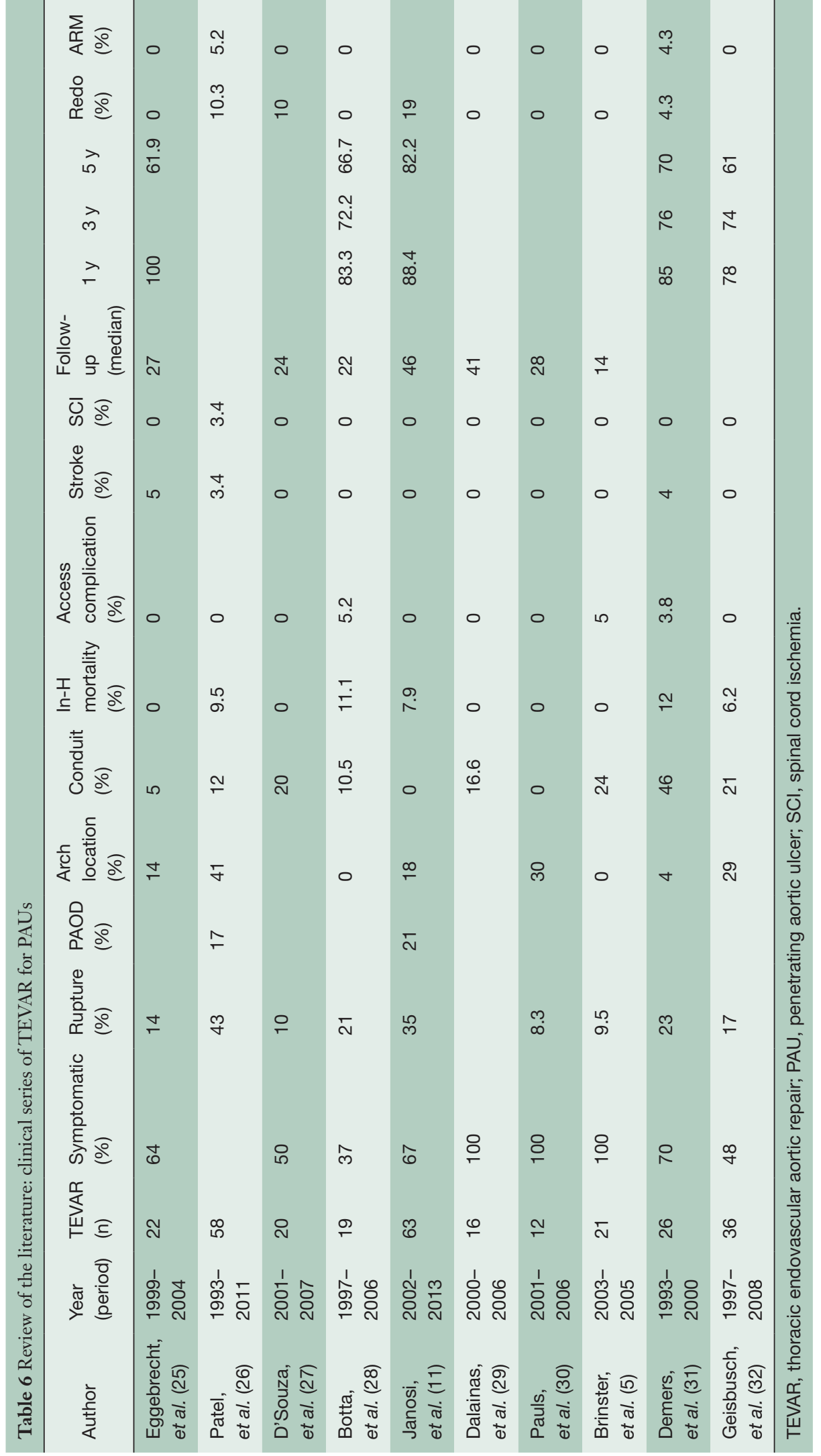


to mortality predicted by the operative risk, our $8.1 \%$ mortality rate for PAU is still too high $(1,16)$. Though our mortality rate is similar to other series reporting $0-12 \%$, this relatively high mortality rate emphasizes the fact that patients with PAU are a high-risk group despite the minimally invasive nature of TEVAR $(5,11,25-32)$. Second, mortality rate remained high during the follow-up period mainly due to cardiovascular events. ARM during followup did not occur in this cohort, but the $63 \%$ overall survival at 4 years is consistent with other series attesting that these patients are high risk and fragile $(11,25,28,31,32)$.

The present study has obvious limitations. First, it is a retrospective study. Second, it has sampling bias in that patients undergoing open repair were not included for comparison. Last, the small number of patients and events makes results of multivariate analysis not generalizable. However, data on PAUs are variable and confounded by heterogeneity of lesions and paucity of long-term follow-up (9). Despite these limitations, our inclusion criteria create a relatively homogeneous cohort and patient follow-up was excellent. Our outcomes adhered systematically to the proßposed guidelines and compare well with other studies $(17,18)$.

In conclusion, our experience reaffirms that access vessel and aortic arch issues remain a major challenge in the performance of TEVAR for PAUs. The cumulative $27 \%$ rate of access/arch issues in our patients is lower than previously reported and may be explained by meticulous evaluation and careful surgical planning as well as device advancements for both access routes and arch anatomy. Patients with PAUs remain a cohort at high risk for TEVAR. Both in-hospital and mid-term mortality rates are high, even in the TEVAR era, a fact that underscores the impact of the high burden of atherosclerotic disease which characterizes these patients.

\section{Acknowledgments}

Authors are very grateful to Mrs Maria Rita Bogni for her assistance with the organization and management of followup evaluations.

\section{Footnote}

Conflicts of Interest: The authors have no conflicts of interest to declare.

\section{References}

1. Evangelista A, Czerny M, Nienaber C, et al.
Interdisciplinary expert consensus on management of type $\mathrm{B}$ intramural haematoma and penetrating aortic ulcer. Eur J Cardiothorac Surg 2015;47:209-17.

2. D'Annoville T, Ozdemir BA, Alric P, et al. Thoracic Endovascular Aortic Repair for Penetrating Aortic Ulcer: Literature Review. Ann Thorac Surg 2016;101:2272-8.

3. Chou AS, Ziganshin BA, Charilaou P, et al. Long-term behavior of aortic intramural hematomas and penetrating ulcers. J Thorac Cardiovasc Surg 2016;151:361-72.

4. Tittle SL, Lynch RJ, Cole PE, et al. Midterm follow-up of penetrating ulcer and intramural hematoma of the aorta. J Thorac Cardiovasc Surg 2002;123:1051-9.

5. Brinster DR, Wheatley GH 3rd, Williams J, et al. Are penetrating aortic ulcers best treated using an endovascular approach? Ann Thorac Surg 2006;82:1688-91.

6. Nathan DP, Boonn W, Lai E, et al. Presentation, complications, and natural history of penetrating atherosclerotic ulcer disease. J Vasc Surg 2012;55:10-5.

7. Bischoff MS, Geisbüsch P, Peters AS, et al. Penetrating aortic ulcer: defining risks and therapeutic strategies. Herz 2011;36:498-504.

8. Ganaha F, Miller DC, Sugimoto K, et al. Prognosis of aortic intramural hematoma with and without penetrating atherosclerotic ulcer: a clinical and radiological analysis. Circulation 2002;106:342-8.

9. Cho KR, Stanson AW, Potter DD, et al. Penetrating atherosclerotic ulcer of the descending thoracic aorta and arch. J Thorac Cardiovasc Surg 2004;127:1393-9.

10. Erbel R, Aboyans V, Boileau C, et al. 2014 ESC Guidelines on the diagnosis and treatment of aortic diseases: Document covering acute and chronic aortic diseases of the thoracic and abdominal aorta of the adult. The Task Force for the Diagnosis and Treatment of Aortic Diseases of the European Society of Cardiology (ESC). Eur Heart J 2014;35:2873-926.

11. Jánosi RA, Gorla R, Tsagakis K, et al. Thoracic Endovascular Repair of Complicated Penetrating Aortic Ulcer: An 11-Year Single-Center Experience. J Endovasc Ther 2016;23:150-9.

12. Williams DM, Cronin P, Dasika N, et al. Aortic branch artery pseudoaneurysms accompanying aortic dissection. Part II. Distinction from penetrating atherosclerotic ulcers. J Vasc Interv Radiol 2006;17:773-81.

13. Gifford SM, Duncan AA, Greiten LE, et al. The natural history and outcomes for thoracic and abdominal penetrating aortic ulcers. J Vasc Surg 2016;63:1182-8.

14. Gutsche JT, Cheung AT, McGarvey ML, et al. Risk factors for perioperative stroke after thoracic endovascular 
aortic repair. Ann Thorac Surg 2007;84:1195-200.

15. Ou P, Bonnet D, Auriacombe L, et al. Late systemic hypertension and aortic arch geometry after successful repair of coarctation of the aorta. Eur Heart J 2004;25:1853-9.

16. Society of Thoracic Surgeons. Committee to develop a national database for thoracic surgeons. Definitions of terms of the Society of Thoracic Surgeons national cardiac surgery database. Ann Thor Surg 1994;58:271-3.

17. Turina MI, Shennib H, Dunning J, et al. EACTS/ ESCVS best practice guidelines for reporting treatment results in the thoracic aorta. Eur J Cardiothorac Surg 2009;35:927-30.

18. Fillinger MF, Greenberg RK, McKinsey JF, et al. Reporting standards for thoracic endovascular aortic repair (TEVAR). J Vasc Surg 2010;52:1022-33.

19. von Allmen RS, Weiss S, Tevaearai HT, et al. Completeness of Follow-Up Determines Validity of Study Findings: Results of a Prospective Repeated Measures Cohort Study. PLoS One 2015;10:e0140817.

20. Criado FJ. Aneurysm morphology matters: fusiform vs. saccular. J Endovasc Ther 2013;20:207-9.

21. Etz CD, Weigang E, Hartert M, et al. Contemporary spinal cord protection during thoracic and thoracoabdominal aortic surgery and endovascular aortic repair: a position paper of the vascular domain of the European Association for Cardio-Thoracic Surgery. Eur J Cardiothorac Surg 2015;47:943-57.

22. Jackson BM, Carpenter JP, Fairman RM, et al. Anatomic exclusion from endovascular repair of thoracic aortic aneurysm. J Vasc Surg 2007;45:662-6.

23. Brinster DR. Endovascular repair of the descending thoracic aorta for penetrating atherosclerotic ulcer disease. J Card Surg 2009;24:203-8.

24. Tsilimparis N, Dayama A, Perez S, et al. Iliac conduits for endovascular repair of aortic pathologies. Eur J Vasc Endovasc Surg 2013;45:443-8.

25. Eggebrecht H, Herold U, Schmermund A, et al. Endovascular stent-graft treatment of penetrating aortic ulcer: results over a median follow-up of 27 months. Am Heart J 2006;151:530-6.

26. Patel HJ, Sood V, Williams DM, et al. Late outcomes with repair of penetrating thoracic aortic ulcers: the merits of an endovascular approach. Ann Thorac Surg 2012;94:516-22.

27. D'Souza S, Duncan A, Aguila F, et al. TEVAR for nonaneurysmal thoracic aortic pathology. Catheter Cardiovasc
Interv 2009;74:783-6.

28. Botta L, Buttazzi K, Russo V, et al. Endovascular repair for penetrating atherosclerotic ulcers of the descending thoracic aorta: early and mid-term results. Ann Thorac Surg 2008;85:987-92.

29. Dalainas I, Nano G, Medda M, et al. Endovascular treatment of penetrating aortic ulcers: mid-term results. Eur J Vasc Endovasc Surg 2007;34:74-8.

30. Pauls S, Orend KH, Sunder-Plassmann L, Endovascular repair of symptomatic penetrating atherosclerotic ulcer of the thoracic aorta. Eur J Vasc Endovasc Surg 2007;34:66-73.

31. Demers P, Miller DC, Mitchell RS, et al. Stent-graft repair of penetrating atherosclerotic ulcers in the descending thoracic aorta: mid-term results. Ann Thorac Surg 2004;77:81-6.

32. Geisbüsch P, Kotelis D, Weber TF, et al. Early and midterm results after endovascular stent graft repair of penetrating aortic ulcers. J Vasc Surg 2008;48:1361-8.

33. Gupta PK, Sundaram A, Kent KC. Morbidity and mortality after use of iliac conduits for endovascular aortic aneurysm repair. J Vasc Surg 2015;62:22-6.

34. Schanzer A, Simons JP, Flahive J, et al. Outcomes of fenestrated and branched endovascular repair of complex abdominal and thoracoabdominal aortic aneurysms. J Vasc Surg 2017;66:687-94.

35. Mariscalco G, Piffaretti G, Tozzi M, et al. Predictive factors for cerebrovascular accidents after thoracic endovascular aortic repair. Ann Thorac Surg 2009;88:1877-81.

36. Eggebrecht H, Thompson M, Rousseau H, et al. European Registry on Endovascular Aortic Repair Complications. Retrograde ascending aortic dissection during or after thoracic aortic stent graft placement: insight from the European registry on endovascular aortic repair complications. Circulation 2009;120:S276-81.

37. Canaud L, Ozdemir BA, Patterson BO, et al. Retrograde aortic dissection after thoracic endovascular aortic repair. Ann Surg 2014;260:389-95.

Cite this article as: Piffaretti G, Fontana F, Tadiello M, Guttadauro C, Piacentino F, Bush RL, Socrate AM, Tozzi M. Arch and access vessel complications in penetrating aortic ulcer managed with thoracic endovascular aortic repair. Ann Cardiothorac Surg 2019;8(4):471-482. doi: 10.21037/ acs.2019.06.07 